\title{
Freedom as a concept and as a property of the subject
}

\author{
Gulnara Nussipova - Galiya Kurmangaliyeva - Manifa Sarkulova - Zhazira \\ Oshakbayeva - Bakhytzhan Orazaliyev - Dasa Porubcanova - Gabriela \\ Gabrhelova
}

DOI: 10.18355/XL.2021.14.03.19

\begin{abstract}
The other side of the alternative of "objectivism or subjectivism (anti-substantialism"), can appropriately resolve the problem of the essence of freedom. Hegel wrote: "No idea can be said with such full right that it is indefinite, ambiguous, accessible to the greatest misunderstandings and therefore is actually subject to them, as about the idea of freedom, and none of them is usually spoken of with such a small degree of understanding of it. Since the free spirit is a real spirit, to the extent that the misunderstandings associated with it have enormous practical consequences..." (Hegel, 1977: 471) Thus, even the idealist Hegel admits that the problem of freedom has theoretical and particular practical significance. One can agree with I. Kant, G. Hegel, and N. Berdyaev, and many other philosophers that freedom exists only in the world of human reality, that is, in culture and society. In nature, both living and nonliving, it is not freedom that occurs but a necessity dialectically associated with chance and possibility. As Hegel rightly pointed out, "Nature ... manifests in its present being not freedom, but necessity and chance" (Hegel, 1975: 695). This statement certainly needs to be concretized. Freedom cannot coincide with necessity, but it cannot entirely resist it. Freedom that is not based on any form of necessity, as Hegel also showed, is not freedom. It is arbitrariness. Naked arbitrariness, according to him, is will in the form of chance (Hegel, 1974). One should bear in mind that the differences between inanimate (physical and chemical reality) and living (biological reality) nature, and in the latter - between the levels of its organization - are qualitative and even essential.
\end{abstract}

Key words: freedom, the concept of freedom, the property of freedom, human subject and freedom

\section{Introduction}

In inanimate nature, even if we assume that it is also intelligent in its own way, there can be no freedom. Its "mind" can only be contained in its internal organization, which is the essence of the formation of one or another. This essence, in interaction with other formations, appears in external exposure, in a phenomenon. Like everything in the universe, any particular final inanimate formation (as the unity of the universal and the individual) has an essence and a phenomenon, internal and external, and other categorical characteristics. The "mind" of such an education consists only of revealing its essence, its internal organization in the most complete and undistorted form, and perceiving external influences, preserving this essence, this organization as much as possible. This relationship among the final formations is called

XLinguae, Volume 14 Issue 3, June 2021, ISSN 1337-8384, eISSN 2453-711X 
interaction. Since each (particular) thing acts in its essence in the process of interaction, to the extent that each of the necessities emanating from each of them is distorted, this distortion effect is nothing more than an accident. Necessity and chance are dialectical opposites, and therefore neither one nor the other is found in its pure form. In addition, there is change and movement in inanimate nature, but there is no evolution or development.

In living nature, the picture is fundamentally different. Firstly, in the plant and animal kingdoms, there is a considerable variety in comparison with inanimate nature; and secondly, there is a pronounced development and continuity in development. In any case, this is not the main issue. The main thing is that there is expediency in living nature. The more developed a living organism is, the more pronounced is the expediency in the manifestation of its life. We will talk about an animal since it is closer to humans on the evolutionary ladder than a plant.

The animal has a set of needs. Therefore, on the one hand, it is more attached to its environment than an inanimate thing. A material object, in principle, is not attached to anything around itself and can exist in a much more comprehensive range of conditions than an animal. For an animal, its environment exists, outside of which it can already perish. The need prescribes selectivity for the animal in its relation to what is in the environment. An inorganic substance does not choose what to interact with and what to ignore. It interacts with everything that collides with everything according to the logic of causality, even to the point of destruction. The animal, so to speak, "orientates itself" in the environment and not only interacts with organic and inorganic phenomena but also avoids interaction with anything that can harm it. In this case, we talk about the instinct of selfpreservation.

\section{Literature Review}

The concept of expediency can be applied to the phenomena of inanimate nature only as a metaphor. The Georgian philosopher N.Z. Chavchavadze argued in this respect that "we can, for example, consider the fall of a stone as purposeful, but such consideration will be elementarily inadequate, erroneous. Considering, for example, the behavior of a monkey, picking a fruit from a tree with a stick, as an expedient process, seems at least much more adequate" (Chavchavadze, 1979: 32). And one more consideration. With regard to physical and chemical phenomena, one can hardly say that they perform any function, or that they are self-governing, capable of receiving and purposefully processing information, that they are capable of self-preservation and development, not to mention reproduction. All this is inherent in living "substance." But what conclusion follows from this? Is necessity disappearing in living nature? Of course, it does not disappear. But it seems to split in two. One form of necessity here is that which comes from the environment and acts on the animal from the outside. In other words, it is an external necessity. Another form of necessity is that which is realized in the objective expediency of animal behavior. Therefore, this is an internal necessity. But in the world of wildlife, there is also an accident. Its origins and forms of manifestation are different. First, chance can come from the 
environment, from the influence of the environment on the animal. But the environment, roughly speaking, is subdivided into living and nonliving. In the realm of the inanimate, the dialectic of chance and necessity acts, as we have already noted. Therefore, either a predominantly necessary influence, or a predominantly accidental one, can come from the environment. So this kind of randomness can exist for an animal. Another type of accident may be one that proceeds from the internal necessity (expediency) of another animal, especially a representative of another species. But the more highly organized and developed an animal is, the less decisive influence is exerted on its action by external accidents. Such an animal is more autonomous, has a greater capacity for inventiveness, etc. And in higher animals, science has discovered a certain degree of intellectual, abstractive activity.

But can it be argued on this basis that freedom exists in the animal kingdom, at least in its highly organized forms? N.Z. Chavchavadze writes: "It is this independence, autonomy, which is a necessary moment in the behavior of living organisms, that is the equivalent of freedom, and the desire to satisfy needs (even if only genetically programmed), that is, to use the gifts of nature as useful, that is, valuable, the desire for self-preservation, for adaptation to the environment and even for overcoming it - the equivalent of goal-setting and purposefulness in human activity" (Chavchavadze, 1979: 15). Chavchavadze (1979: 16) further clarifies that "these moments do not play a leading role in the development of nature, since their very action is conditioned, determined and placed within the framework of causally acting external factors." The final conclusion to which he comes is the following:

"The presence of elements of freedom (or, rather, its embryos) in nature, even in organic, should not, of course, be exaggerated. The 'self' in which we want to see the equivalent of freedom in the lower forms of development is, of course, not freedom, but rather its possibility, an anticipation of what it will become in the higher forms of reality. In addition, it is suppressed by the innumerable influences of circumstances and phenomena external to this 'self,' almost dissolved in the endless element of necessity" (Chavchavadze, 1979: 18).

\section{State of the Problem}

It is necessary to touch upon the problem of free will and the problem of freedom of choice. Freedom as such is not reduced to either free will or freedom of choice, although it so happens that it is identified with the latter. Will is only one of the "compartments" of consciousness, not the entire consciousness or its center. Consciousness does not belong to will, but the will belongs to consciousness. The will may contain some elements of the subconscious and the unconscious (it is no coincidence that it is sometimes considered irrational). But, be that as it may, the person acts, making volitional decisions, the whole person as a whole. And this is the subject of activity and relations with other subjects. Hegel notes that "the will, which remains at the level of arbitrariness, even when it decides in favor of what is true and just in its content, still suffers from the vainglorious notion that, if it

XLinguae, Volume 14 Issue 3, June 2021, ISSN 1337-8384, eISSN 2453-711X 
pleased it, it could also decide in favor of another deed" (Hegel, 1974: 319). In addition, in the case of arbitrariness, any "restriction of attraction, lust, passion belonging only to a private person as such, restriction of arbitrariness is taken as a restriction of freedom." (Hegel, 1974: 319)

It seems to us that this and similar reasoning does not consider a number of arguments of the position that do not recognize the presence of freedom and the elements, the embryos of freedom in the animal kingdom in the strict sense of this concept. First of all, it is not taken into account that the transition from one "form of movement" (as it was called in dialectical materialism) to another, or - in a different terminology - from one level of organization of reality to another is not evolutionary, but a revolutionary, abrupt transition. There is no gradual, smooth transition between inanimate and living nature. The transition from the inanimate to the living is a qualitative and essential transition; that is, it occurs both at the level of quality and the level of essence. In this process, the removal (Aufheben) of the previous forms occurs, not just their quantitative change.

The difference between the most highly organized animal and the lowest developed man is fundamental. K. Marx wrote as early as 1844 that "The animal is directly identical with its life activity. It is this vital activity. Man makes his very life activity an object of his will and his consciousness. His life activity is conscious. This is not such a certainty with which he directly merges into one. Conscious life activity directly distinguishes a person from animal life" (Marx: 1979; cited in: Chavchavadze, 1979: 93). An animal cannot make its life activity an object for itself; it can only develop some kind of abstraction about external things and operate with them. A person can therefore make his life activity an object for himself because he, in an objective way, refers to all the reality around him. This relationship is nothing more than objective activity.

The animal's attitude to its environment is adaptive. And besides, this attitude is not developed by these particular animals. An animal belongs to its own species, and it is the species, through the mechanisms of heredity, that defines the way of an adequate attitude to the environment. Man's objective activity is not an adaptation to nature. On the contrary, a person by this activity adapts nature to his needs, interests, goals.

\section{Discussion}

In his active relation to reality, a person assimilates the properties and laws of this reality and thereby enriches his activity, making it ever more universal. In this sense, the human activity becomes developed to the extent man has fully and consistently mastered and de-objectified the surroundings and his own nature. By de-objectifying nature, man builds culture and thereby becomes a subject of culture. But objective activity is not only the relation of man to nature; it is also, first of all, the social relation of man to man. Philosophically speaking, it is the unity of the relationship "subject - object" and "object - subject." And these are not two different, heterogeneous types of relations, but only two forms of the same relationship. In this sense, society as a whole is a product of human relationships. However, by creating a society, people create themselves as socially (moreover, concretely) unique 
people. G.S. Batishchev reminds us that "it is impossible to understand the concreteness of a person if one interprets the individual as something derivative, as a kind of secondary product in relation to the primary SocietySubject. However, it is equally true that human society cannot be explained as a secondary product of individuals who would have been subjects before they created society and outside it, that is, primary non-social individualssubjects" (Batishchev, 2015: 279). But this is exactly how the representatives of the theory of social contract interpreted the emergence of society (which they identified with the state). K. Marx wrote: "A person is in the most literal

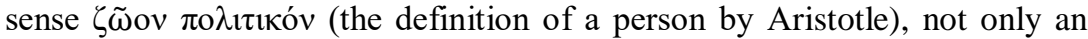
animal, which is characterized by communication, but an animal that can only be isolated in society" (Marx, 1968: 452). Therefore, freedom is also a socio-cultural phenomenon, like everything in the world of human reality. Human objective activity is creativity. Creativity, however, is an integral activity, an activity of an integral person. "Man," writes Zh. M. Abdildin, "acts as an active, free and creative being, a free and creative being, not by any one side of his activity, but as a whole, in his concept ..." (Abdildin, 1989: 112)

Man, creating the world of culture and through this - himself as a subject of this world, masters and creatively develops the kingdom of necessities. Thus, as V. Frankl notes, "a person is a being that transcends necessity" (Frankl, 1990: 93). Natural necessity is removed in the process of man's assimilation of nature and creation of his own world of culture. The kingdom of necessity is removed in the kingdom of freedom. This means that necessity, not being eliminated from the architectonics of freedom, takes a subordinate place in this architectonics and at the same time is transformed ("humanized"). S.A. Levitsky writes: "The concept of necessity does not require the concept of freedom, but the concept of freedom requires the concept of necessity as its natural counterweight" (Levitsky, 1995: 98). V. Frankl goes further, arguing that "Necessity and freedom are not localized at the same level; freedom rises, built on top of any need" (Frankl, 1990: 93). Consequently, freedom and necessity as such are not at the same ontological level, but at different ones. Freedom, which has removed and transformed within itself natural necessity, is at a higher ontological level when compared with purely natural necessity and is irreducible to it.

If we accept the unity, almost reaching the identity of freedom and creativity, as a fact, then how does it compare with other important categories, such as necessity and chance? It can be noted here that for man as a being of social necessity, necessity appears in two forms - as internal and as external. Internal necessity is, in its most general form, his freedom. Freedom cannot be unnecessary in relation to a person; it cannot be something accidental. At the same time, contrary to the objectivist attitude, freedom is by no means a continuation of natural necessity. This is a different kind of reality. In his activity, man denies, overcomes purely natural necessity, and develops a different logic of behavior and action, which is freedom. Freedom becomes the "core" of human existence, its own inner necessity. Natural necessity is

XLinguae, Volume 14 Issue 3, June 2021, ISSN 1337-8384, eISSN 2453-711X 
an external necessity for man. The activity that assimilates nature, including cognitive, is aimed at it.

But, contrary to Hegel and Engels, freedom is not a cognized necessity. If it were so, then man should be understood as an adaptive being with a developed consciousness. After all, necessity does not disappear because it has become known. It is just that a person has the opportunity to adapt to it at the lowest cost. But the cognition of necessities, one's knowledge of them, is at the same time a moment of freedom. The more developed a person is, the greater the number of natural necessities he cognizes and subordinates to his power. Of course, there may be (and there are) such natural necessities that he is unaware of for the time being; there are those that he knows about but cannot yet cope with them.

G.S. Batishchev opines that "Freedom is not a condition of human activity obtained or introduced from outside, it is the immanent nature of the very active essence of man - the essence of man as an independent subject. Freedom is only an internal ability, adequate to the level of progressive development and wealth of this essence" (Batishchev, 2015: 138) (we are talking about the essence of man). This means that the situation with external necessity is the same as with all conditions and circumstances of human activity. K. Marx noted that "both objective and subjective conditions ... represent only two different forms of the same conditions" (Marx, 1969: 695). Man makes conditions the object of his activity; in other words, he conditions himself. If a person cannot make conditions and circumstances an object of his activity, then such a person is not yet sufficiently developed for this. In this case, a person directly or indirectly depends on them. Thus, the true alternative to freedom is not necessity, but dependence. And this dependence belongs to the spectrum of necessities that rigidly condition a person, but he is not able to subordinate them to his power. Thus, primitive man was multilaterally dependent both on nature and on his social whole (in this whole, relations of personal dependence prevailed).

From what has been said, it is clear that freedom is a historically developing, human-enhanced phenomenon. As Engels noted, freedom "is a necessary product of historical development. The first people to emerge from the animal kingdom were in all essentials just as unfree as the animals themselves; but every step forward on the path of culture was a step towards freedom" (Engels, 1961: 338). G.S. Batishchev's statement about the essence of freedom can be somewhat concretized. Freedom, in our opinion, consists not only in the action of a person in accordance with the level of development of his essence, but also in the development of this essence, in the development of his activity and his inter-human relations. Then the coincidence of freedom and creativity will be authentic. Indeed, only under this condition can a person be defined as a completely creative being, and creativity and freedom will appear as two names for the same way of human existence.

But man is a social being. He lives and acts in society. Consequently, freedom should be determined not only in relation to nature but also in relation to society, that is, in relation to other people. When K. Marx asserts that society is "the person himself in his social relations" (Marx, 1969: 553), 
then this is true at the level of essence. But the essence in its existence does not coincide with itself. Marx's position is fulfilled only in relation to the essence of society. At this level, a free society is a society in which, as I. Kant noted, "the freedom of everyone is compatible with the freedom of everyone else ..." (Kant, 1963: 337). Marx and Engels expressed themselves even more categorically: this is a society in which "the free development of everyone is a condition for the free development of all" (Marx, 1955: 423). But such a society is only an ideal. However, the true essence of man, and hence freedom, is only that which corresponds to its ideal.

In accordance with this essence and at the same time the ideal, it can be argued that freedom cannot be a means for anything. In this sense, one can agree with the words of J. P. Sartre that "freedom cannot have any other goal than itself ..." (Sartre, 1994: 198), and the words of E. Fromm that "human existence and the vault are inseparable from the very beginning" (Fromm, 1995: 258).

But real societies throughout history have little corresponded to their essence as an essence-ideal. In them, existence prevailed over essence and, as it were, pushed it to the periphery. The old principle is at work here: the freedom of one rests against the freedom of another. Or, in other words: the limits of freedom of one are the beginning of freedom of another. Here everyone praises freedom, but ... as a rule, his own. "Not a single person," writes K. Marx, "fights against freedom, - a person fights, at most, against the freedom of others" (Marx, 1955: 339). With regard to this situation, it is customary to distinguish between negative freedom and positive freedom. Regarding the first, everyone agrees that this is nothing more than "freedom from ...". It is negative because it is based not on itself, but on repulsion from something concrete, on the denial of it. It therefore constantly correlates with this negative phenomenon and thus constantly presupposes its existence. Without him, there is nothing to say about her. E. Fromm, therefore, writes that "Freedom from" "...is not identical to positive freedom" (Fromm, 1995: 168). Many people understand positive freedom as "freedom of what..." (for example, freedom of speech) or "freedom for..." (for example, freedom to play sports). It should be noted that E. Fromm interprets positive freedom in a very peculiar way. According to him, "positive freedom consists in the spontaneous activity of the entire integral personality of a person" (Fromm, 1995: 171). At the same time, he concretizes this thesis by explaining that the "most important component of such spontaneity is love ... Another component of spontaneity is work" (Fromm, 1995: 174). However, spontaneity is a process that is not subject to conscious control and regulation. Therefore, he cannot be considered free in the proper sense of the given concept.

In fact, the positive nature of this type of freedom is imaginary. After all, anything to which a person devotes himself, turning away from unfreedom, from dependence, is finite. He actually binds himself to it and therefore depends on it. This form of freedom is not a consistent alternative to negative freedom and, in fact, turns out to be only a disguised unfreedom dressed up in the clothes of freedom. Although, of course, "freedom for ..." is preferable to

XLinguae, Volume 14 Issue 3, June 2021, ISSN 1337-8384, eISSN 2453-711X 
"freedom from ...". Therefore, in our opinion, G.S. Batishchev is right when he writes that freedom "is neither 'freedom from' something, from some purely external restriction, because all social restrictions are reproduced only by human activity itself, nor 'freedom for' something, because it can have a goal only in itself' (Batishchev, 2015: 221).

There is also the notion that freedom is associated with domination, and lack of freedom, dependence - with slavery. So, A. Camus suggests that "To know whether a person is free, it is enough to know whether he has a master" (Camus, 1990: 138). If there is a master, then one is not free; if there is none, then one is free. There is nothing to object to. But such a question is possible. A person who has a master is not free; but is the master himself free? In the previous section, it was shown that Hegel, in his "Phenomenology of Spirit," revealed the dialectic of the slave and the master and proved that the master is also not free. In his work "On Slavery and Human Freedom," N.A. Berdyaev showed that genuine positive freedom is outside the relationship "domination - slavery."

Philosophers also distinguish between internal and external freedom. We agree with this distinction. In our opinion, external freedom should be understood as the whole system of natural and socio-cultural conditions and circumstances that in one way or another determine the activity and creativity of man. External freedom is a phenomenon external to a person. And if we abstract from the system of natural determinations, then external freedom is a system of socially given norms and restrictions, prohibitions and prescriptions that outline the boundaries of a person's self-realization, no matter what form and content it may be (from real freedom to arbitrariness and even to anti-human actions). A.A. Khamidov argues that:

"External freedom is freedom provided to a person by a certain authority, by a certain community (group, clan, ethnic group, party, society, state) in accordance with the norms, values, imperatives (one or another form of morality, tradition, legal regulations, etc.). Forms of external freedom are the product of conventionality, or they are developed by special authorities and imposed on people from top to bottom. The system of external freedom includes the so-called human rights, various kinds of 'freedoms' (freedom of speech, freedom of the press, freedom of assembly, etc., etc.).

Internal freedom is that freedom that is developed by the spiritual and spiritual world of each person in accordance with the norms, values, imperatives accepted by him, and which each time corresponds to the level of development and perfection of this world. Internal freedom often (if not always) experiences a regulatory and controlling influence on the part of certain groups, clans, parties, etc., up to the share of society as a whole, the external freedom constructed by which can both stimulate and block the manifestation of internal freedom and the exercise of creativity. But without a sufficiently developed internal freedom, external freedom gives little, and most often gives only negative (both for society and for the 'free' itself). In this case, a person, as 
a rule, is not able to properly use external freedom. This - internal

- freedom, we add, lies in the objectivity of the subject's relationship to the World" (Khamidov, 2014: 228).

Inner freedom is the inalienable property of a person, his ability to act, act and behave in accordance with the level of his creative abilities and capabilities and make overcoming (transcending) the achieved level. S.A. Levitsky notes that "freedom is always a way out of the given circle, there is a breakthrough to the new, there is the introduction of novelty into being, there is the discretion and realization of new values. This is the eternal youth of creativity, the eternal youth of freedom" (Levitsky, 1995: 321). In other words, real freedom is a way of being for creativity. The leading, determining factor should be inner freedom. External freedom in this case exists for the internal, and not vice versa. After all, if we take the culture and the system of social relations, then they are created by the people themselves, that is, freedom, the inner freedom of everyone, participates in their creation. Culture and the system of social relations also become the arena of external freedom to the extent that it is mastered by a person. That which is not mastered, but restricts or suppresses human activity, limits not only his internal, but also external freedom. In this case, one should speak of dependence, that is, the absence of any freedom.

In the course of anthroposociogenesis, not only the physical body of a person was cultivated, but also his psyche. Consequently, will should also be regarded not as a natural psychic, but as a cultural-historical phenomenon. Free will is based on experience, knowledge. F. Engels thus insisted that "Freedom of will means, therefore, nothing more than the ability to make decisions with knowledge of the matter" (Engels, 1961: 459). Thus, the will is free not when it relies only and exclusively on internal mental motivation (as a rule, emotionally colored), but also on extra-psychic objective reality, on objective logic, that is, when it acts as a form of an objective relationship, a relationship focused on the subject's own logic. At the same time, one should agree with those authors who argue that the actual deep mechanisms of free will are still far from being revealed.

Close to the topic of free will, as noted above, is the problem of freedom of choice. For some philosophical trends, freedom of choice is identical to freedom as such. The choice, of course, is always made by the person himself. Freedom of choice, according to Hegel, "this is formal freedom and should be regarded as only imaginary freedom..." (Hegel, 1974: 369). This form of "freedom" is entirely negative. In addition, the spectrum of the selectable can also be pre-defined. This means that the choice will only be free when a person, choosing, acts in accordance with his human essence. Then choice will be an element of freedom in general, just as freedom of will is another aspect of it. But the essence of man in its existence throughout human history did not coincide. Human real history began not with freedom, but with dependence. For many millennia, these were relations of personal dependence. Since the New Time in Western Europe, relations of material dependence came into force and humanity entered the era of alienation. In all historically existing and currently existing societies based on the division of

XLinguae, Volume 14 Issue 3, June 2021, ISSN 1337-8384, eISSN 2453-711X 
labor, the presence of the state, law and other social forces dominating people, social necessity and human freedom are not only divorced, but also polarized relative to each other. In these conditions, freedom appears in various modifications and forms in accordance with the structure of society, with the system of its subdivisions. So, there is economic, political, legal freedom, freedom of thought, speech, press, assembly, religion, etc. Moreover, in some types of societies, they can appear in one guise, in others - in another, in some, there may be a whole set of Freedoms, in others - only a few.

In relation to the individual, the society standing above him appears as an external force, as an external necessity, in contrast to his freedom as an internal necessity. Society dictates to the individual tasks, goals, functions, the very expediency of which for the individual appears as external. In the light of the above, external freedom is nothing more than a system of conditions (economic, political, ideological, legal, etc.) created by society or won by an individual from society, which to one degree or another ensure the realization of the individual's internal freedom within the framework of society. This freedom (or these freedoms) is designed for a certain average citizen of the state, and therefore it appears for different groups of people and concrete individuals as freedom of varying degrees (and for some, perhaps, as non-freedom).

Inner freedom, as noted above, refers to the inner, mental and spiritual world of a person, to the so-called "inner man" (Kolchigin, 1875), and is his personal property. And although this freedom has all the basic attributes common to all, just as the human essence is common to all people, nevertheless, it can be inherent in a given form only to this particular individual. Freedom, as N. A. Berdyaev noted, cannot be obtained from outside, it cannot be imposed, etc. It is also impossible to be free for someone and instead of someone. Freedom can only be worked out for each individual person. That is why, as Berdyaev noted, it is a difficult matter. Freedom inner freedom, of course, is developed by everyone, and all the essential forces of man, all his individual experience and, if possible, the experience of historical humanity, all real and ideal relations to other people, to society, history, and nature should participate in this development. And the richer the inner freedom of the individual, the more it is developed as a subject.

Of course, inner freedom is inseparable from outer; without it, if it is not defective, then at least it is limited in its manifestation and realization. One should not, of course, exaggerate the importance and role of internal freedom in the life of an individual, but nevertheless, it is ultimately (precisely ultimately) determinative of external freedom. And from such an understanding follows the conclusion that any social transformations in the direction of increasing or expanding freedom should be adjusted to it, and not vice versa, striving to adjust the life of the individual to the framework of external freedom. Otherwise, good intentions can turn into failure, if not evil.

\section{Conclusion}

With regard to freedom of choice, clarification is necessary in light of what has been said above about the relationship between society and individuals in 
the real historical process. In this situation, not every choice can be free. An individual can be put in a situation where it is necessary to choose between two or more options that equally do not suit him, limiting his freedom to one degree or another. In addition, consciousness itself, with the help of which an individual makes a choice, can also be not free. So, in some circumstances, especially in totalitarian regimes, there is massive ideological processing of the consciousness of individuals. A comprehensively processed consciousness is not capable of making an objectively free choice. The same applies to free will. It, too, can fall under the influence of advertising, propaganda, etc., and therefore be only illusory-free.

So, all creativity is a manifestation of freedom. But freedom, unless it is interpreted as unlimited arbitrariness, always has some boundaries or limitations. In other words, it is inextricably linked with responsibility. S.A. Levitsky reminds us that "True freedom is not an irresponsible game of possibilities, but the realization of one's unique possibilities, burdened with responsibility" (Levitsky, 1995: 289). F. Engels also noted that "the first condition of any freedom is responsibility ..." (Engels, 1961: 331) S. L. Frank also argued that "no genuine creativity is possible without moral seriousness and responsibility; it requires a moral effort of truthfulness, must be combined with humility, performed through the austerity of selfless service" (Frank, 1997: 238). "Responsibility," notes V.E. Frankl, "belongs to irreducible human phenomena. Like spirituality and freedom, it is a primary phenomenon and not an epiphenomenon" (Frankl, 1990: 198). A person can and should bear full responsibility only if there is freedom itself (external and/or internal). If a person is deprived of external and/or internal freedom, his responsibility cannot be free. In this case, only unfree responsibility can be imposed on him from the outside. But there is one nuance here. Responsibility itself - both free and unfree - can be, like freedom, external and internal. External responsibility is responsibility to external authorities, that is, to those that provide a person with external freedom. $\mathrm{He}$ is responsible to them for the results of his deeds, behavior, and deeds.

External - both legal and ethical - responsibility can be removed from a person, but internal - cannot because only the person himself can remove it. "But, guilt is also connected with responsibility," Bakhtin (2003: 239) insists correctly, and we concur with this view. "Personality," he adds, "must become completely responsible: all its moments must not only fit side by side in the time series of his life, but penetrate each other in the unity of guilt and responsibility" (Bakhtin, 2003: 243). Like freedom and responsibility, guilt is also external and internal. External guilt is guilt before the external social reality in all its diversity; inner guilt is guilt before one's inner soul-spiritual world, before one's conscience, before - finally - one's human essence. Internal guilt is also self-judgment. M.K. Mamardashvili writes in this regard that:

“...Society and history can punish us, but with how society punished - say, we were given five years in prison - we can live with this, we can live with it. But about something that a person addresses to himself sometimes, it is impossible to live. That is, it

XLinguae, Volume 14 Issue 3, June 2021, ISSN 1337-8384, eISSN 2453-711X 
is more serious than any assessment arising from specific moral and legal principles" (Mamardashvili, 1994: 79).

This is the true unity of guilt and responsibility. Thus, human creativity, by its attributes, has, first of all, internal freedom and internal responsibility. External freedom and external responsibility are only its external conditions and external constraints.

\section{Bibliographic references}

ABDILDIN, Zh. 1989. Freedom as a measure of the transformation of an object. Dialectics of freedom as creativity. Alma-Ata: Nauka. pp. 95-112.

BAKHTIN, M. M. 2003. Art and responsibility. Bakhtin M. M. Collected works. In 7 volumes. V. 1. Philosophical aesthetics of the 1920p. Moscow: Russian dictionaries; Languages of Slavic Culture, pp. 5-6.

BATISHCHEV, G.S. 2015. Activity essence of man as a philosophical principle. Batishchev GS Selected works. - Almaty: IFPR, pp. 191-275.

CAMUS, A. 1990. The myth of Sisyphus. Essay on absurdity. Camus A. Rebellious man. Philosophy. Politics. Art. Moscow: Politizdat, pp. 23-100.

CHAVCHAVADZE, N.Z. 1979. External and internal factors of cultural development. Culture and social development. Tbilisi: Metsniereba, pp.5-32.

ENGELS, F. 1961. Letter to A. Bebel. London, March 18-28, 1875. K. Marks, F. Engels Works. Ed. 2nd. T. 19. Moscow: Politizdat, pp. 1-8.

FRANK, S. L. 1997. Reality and man. Metaphysics of human existence. Frank S. L. Reality and man. Moscow: Republic, p. 207-450.

FRANKL, V. 1990. Spirituality, freedom and responsibility. Frankl V. Man in search of meaning. Moscow: Progress, pp. 93-129.

FROMM, E. 1995. Escape from freedom. Ed. 2nd. Moscow: Ed. group "Progress", "Univers". $253 \mathrm{p}$.

HEGEL, G. V. F. 1977. Encyclopedia of Philosophical Sciences. T. 3. Philosophy of the Spirit. Moscow: Mysl. 471 p.

HEGEL, G. V. F. 1975. Encyclopedia of Philosophical Sciences. T. 2. Philosophy of nature. Moscow: Mysl. 695 p.

HEGEL, G. V. F. 1974. Encyclopedia of Philosophical Sciences. T. 1. Science of logic. Moscow: Mysl, 452 p.

HEGEL, G. V. F. 1993. Lectures on the philosophy of history. SPb.: Nauka. 479 p.

KANT, I. 1963. Criticism of pure reason. Kant I. Works. In 6 volumes v. 3. Moscow: Mysl. 799 p.

KHAMIDOV, A.A. 2014. Freedom of scientific creativity and responsibility of a scientist. Almaty: IFPR KN MES RK. 301 p.

KOLCHIGIN, S. Yu. 2015. The Inner Man. Alma-Ata: SaGa, 295 p.

LEVITSKY, S. A. 1995. Tragedy of freedom. T. 1. Moscow: Canon, 512 p.

MAMARDASHVILI, M.K. 1994. Philosophy and personality. Man. No. 5.

pp. 5-19.

MARX, K. 1955. Debate of the Sixth Rhine Landtag. Article one. Debate on freedom of the press and on the publication of the protocols of the estate meeting. Marks, F. Engels Works. Ed. 2nd. T. 1. M.: Politizdat, pp. 30-84.

MARX, F. 1955. Engels Manifesto of the Communist Party. K. Marx, F. Engels Works. Ed. 2nd. T. 4. M.: Politizdat, pp. 419-459.

RYABCHENKO, O.N. - PROKOPYEV, A.I. - ROMANCHENKO, L.N. KORZHUEV, A.V. - KROKHINA, J.A. 2018. Social and philosophical understanding of national and civic identity in the context of interethnic and interreligious conflict risks. In: Xlinguae. vol. 11, n. 2, pp. 359-369 ISSN 2453-711X DOI: $10.18355 /$ XL.2018.11.02.29 
SARTRE, J.-P. 1994. Existentialism is humanism. Sartre J.-P. Nausea. Selected works. MOSCOW: Republic, pp. 435-469.

Words: 6613

Characters: 41168 (22,87 standard pages)

Nussipova Gulnara

Political Science and Religious Studies

Science Committee of the Ministry of Education and Science of the Republic of

Kazakhstan, st. Kurmangazy, 29

050010 Almaty

Kazakhstan

Assoc. Prof. Dr. Kurmangaliyeva Galiya

Institute of Philosophy,

Political Science and Religious Studies

Science Committee of the Ministry of Education and Science of the Republic of Kazakhstan, st. Kurmangazy, 29

050010 Almaty

Kazakhstan

feruza.utegenovna@mail.ru

Sarkulova Manifa

Eurasian National University named after L.Gumilev

Satbayev street 2, city Nur-Sultan

Kazakhstan

Oshakbayeva Zhazira, PhD.

Institute of Philosophy, Political Science and Religious Studies

Science Committee of the Ministry of Education and Science of the Republic of Kazakhstan, st. Kurmangazy, 29, 050010 Almaty

Kazakhstan

Orazaliyev Bakhytzhan

Eurasian National University named after L.Gumilev

Satbayev street 2, city Nur-Sultan

Kazakhstan

karmenov_a@mail.ru

doc. PaedDr. Dáša Porubčanová, PhD.

corresponding author

DTI University, Dubnica nad Váhom

Slovakia

porubcanova@dti

ORCID ID: https://orcid.org0000-0001-5287-682X

doc. PhDr. PaedDr. Gabriela Gabrhelová, PhD.

DTI University

Dubnica nad Váhom

Slovakia

gabrhelova@dti.sk

XLinguae, Volume 14 Issue 3, June 2021, ISSN 1337-8384, eISSN 2453-711X 